Original Research

\title{
Measurements of Overwater Gust Factor from Near Surface to Beyond Common Hub Height: A Case Study
}

Shih-Ang Hsu *

Coastal Studies Institute, Louisiana State University, Baton Rouge, LA 70803, USA; E-Mail: sahsu@lsu.edu

* Correspondence: Shih-Ang Hsu; E-Mail: sahsu@lsu.edu

Academic Editor: Aritra Ghosh

Special Issue: Progress of Wind Energy Technology and Its Maintenance

Journal of Energy and Power Technology

2021, volume 3, issue 3

doi:10.21926/jept.2103031
Received: December 13, 2020

Accepted: July 01, 2021

Published: July 06, 2021

\begin{abstract}
In September 2020 Hurricane Sally affected the north central Gulf of Mexico. Making use of the anemometers data available at 4 oil rigs over the affected region, it is found that, when the atmospheric stability was near-neutral, the gust factor $(G)$ decreases linearly with height from approximately 1.28 at $35 \mathrm{~m}$ above the sea surface to 1.18 at $160 \mathrm{~m}$. In other words, $G$ decreases linearly at the rate around $8 \%$ per $100 \mathrm{~m}$ from the typical hub height to beyond common hub height. Based on the linear equation found in this study, the $G$ extrapolated to the standard height of $10 \mathrm{~m}$ is approximately 1.3 which is also consistent with that measured at two buoys over the affected region. Therefore, a $G$ of 1.3 at near surface may be useful for offshore wind energy R\&D and O\&M, particularly for those regions affected by tropical cyclones.
\end{abstract}

\section{Keywords}

Offshore wind energy; overwater gust factor; ASOS measurements; NDBC buoy measurements; hurricane Sally (2020)

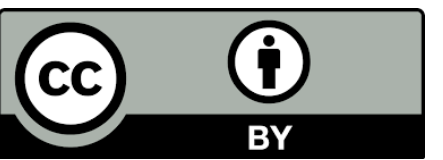

(C) 2021 by the author. This is an open access article distributed under the conditions of the Creative Commons by Attribution License, which permits unrestricted use, distribution, and reproduction in any medium or format, provided the original work is correctly cited. 


\section{Introduction}

Knowledge of overwater gust factor ( $G=U_{\text {gust }} / U_{z}$, here $U_{\text {gust }}$ is the gust measurement and $U_{z}$ is the sustained wind speed at height $Z$ ) is essential for all phases of offshore wind energy production from prospecting including resource assessment research and development (R\&D) to operation and maintenance ( $O \& M)$, see e.g. [1-5]. While most research related to $G$ was devoted to near surface or the hub height around $80 \mathrm{~m}$ (meters) [6-8], information on the vertical distribution of $G$ higher than hub height is lacking, particular in tropical-cyclone prone regions around the world where offshore wind energy may be potentially available. Therefore, it is the purpose of this study to provide wind energy engineers with such information. As shown in Figure 1, the area selected is located over the north central Gulf of Mexico since there are several oil rigs which have routine wind measurements at heights ranging from 35 to $160 \mathrm{~m}$ above the mean sea level. The dates and time in UTC were from 14 to 16 September 2020 when Hurricane Sally was in the area, see the websites of National Hurricane Center (NHC) at www.nhc.noaa.gov and the National Data Buoy Center (NDBC) at www.ndbc.noaa.gov for detail.

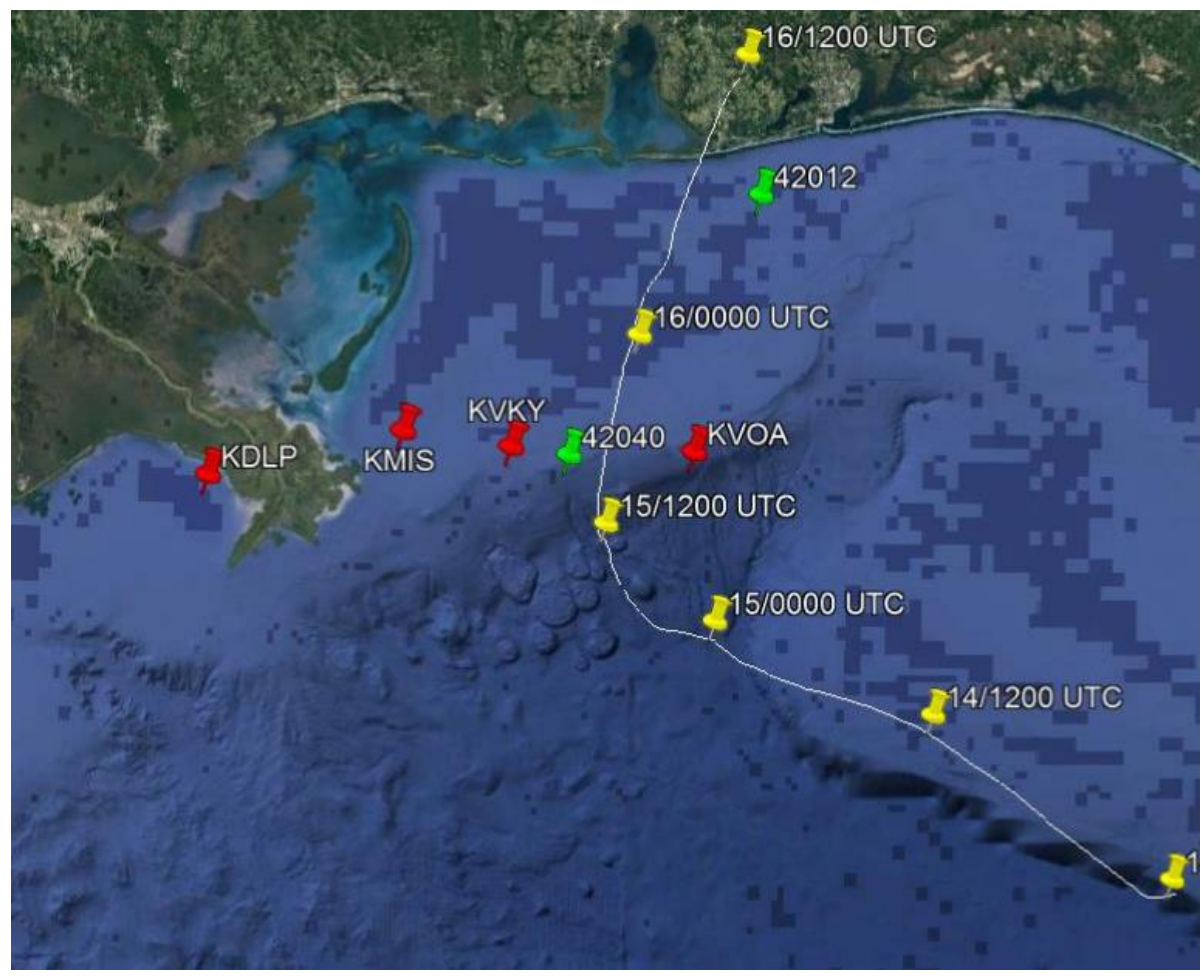

Figure 1 Track of Hurricane Sally (in yellow pins) and measurement stations (green pins for NDBC buoys and red pins for oil rigs) on 14-16 September 2020 when Sally was affecting the north central Gulf of Mexico. Storm track data of Sally is obtained from NOAA at www.nhc.noaa.gov/data/trc/. Time is in UTC and only 12-hour intervals are plotted for clarity.

\section{The Measurements}

Four oil rigs over the north central Gulf of Mexico were affected during the passage of Hurricane Sally in September 2020 (see Figure 1). They were KDLP with its anemometer located at 34.7m, KMIS at $85 \mathrm{~m}, \mathrm{KVKY}$ at $115 \mathrm{~m}$ and KVOA at $160 \mathrm{~m}$, respectively. The anemometers at the 4 oil rigs are 
parts of the standard Automatic Surface Observing System (ASOS) so that the sampling durations for $U_{\text {gust }}$ and $U_{z}$ are 5 seconds and 2 minutes, respectively. Real time data during the passage of Sally were acquired from the NDBC website. The gust factor $G$ at each of these 4 stations during the passage of Sally is determined from the slop of the scatter plot of gust and wind speed as presented in Figure 2. Note that these ASOS data are also available from the archives, for KVOA at https://mesonet.agron.iastate.edu/sites/locate.php?network=LA_ASOS, for KDLP and KMIS at https://mesonet.agron.iastate.edu/sites/locate.php?network=MS_ASOS, and for KVKY at https://mesonet.agron.iastate.edu/sites/locate.php?network=TX_ASOS, respectively.

a

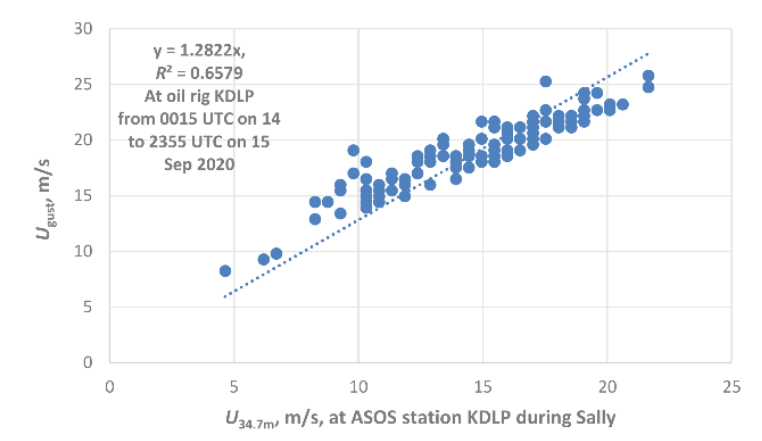

C

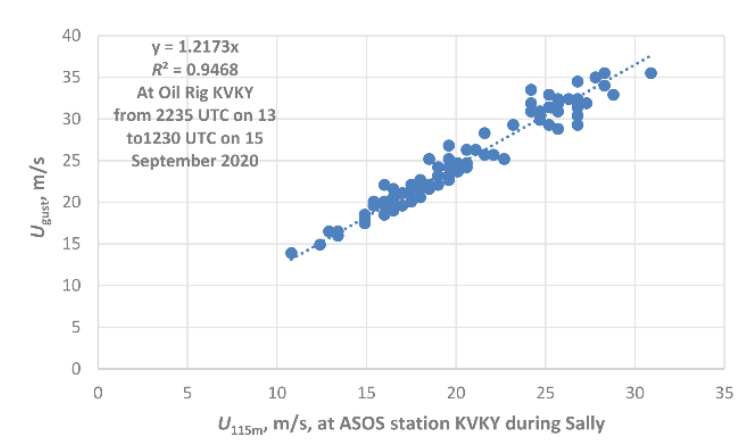

b

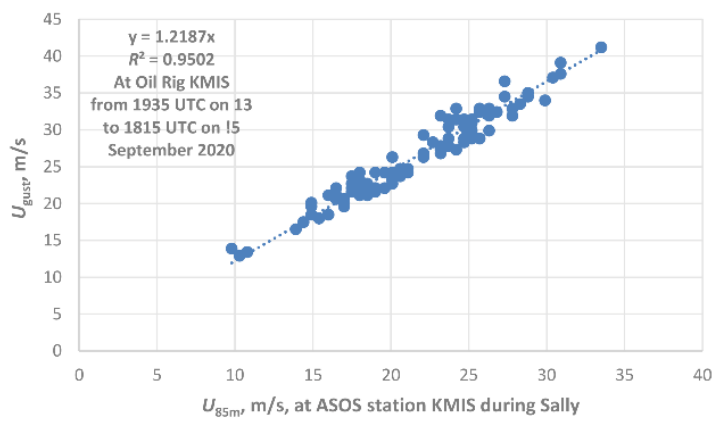

d

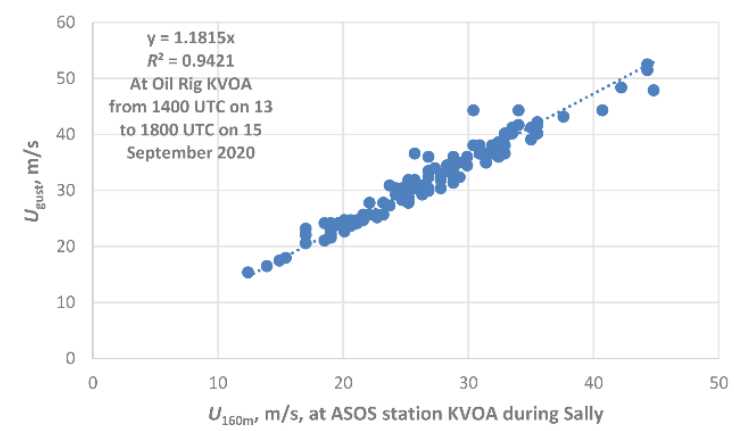

Figure 2 a) Measurements of wind speed and gust at $34.7 \mathrm{~m}$ at Oil Rig KDLP; b) Measurements of wind speed and gust at $85 \mathrm{~m}$ at Oil Rig KMIS; c) Measurements of wind speed and gust at $115 \mathrm{~m}$ at Oil Rig KVKY; d) Measurements of wind speed and gust at $160 \mathrm{~m}$ at Oil Rig KVOA.

\section{Results}

Based on the gust factors found at the 4 ASOS stations of different anemometer heights (Figure 2 ), the variations of $G$ with height from 34.7 to $160 \mathrm{~m}$ is presented in Figure 3 . The result indicates that

$$
G=1.30-0.0008 Z \text {. }
$$

with a coefficient of determination, $R^{2}=0.92$. Here $Z$ is the height in meters. Figure 3 indicates that the gust factor decreases linearly with height from 1.28 at $34.7 \mathrm{~m}$ above the sea surface to 1.18 at 
$160 \mathrm{~m}$. The rate of the drop is approximately $8 \%$ per $100 \mathrm{~m}$. By setting $Z=10 \mathrm{~m}$, we have $G_{10 \mathrm{~m}}=$ 1.3.

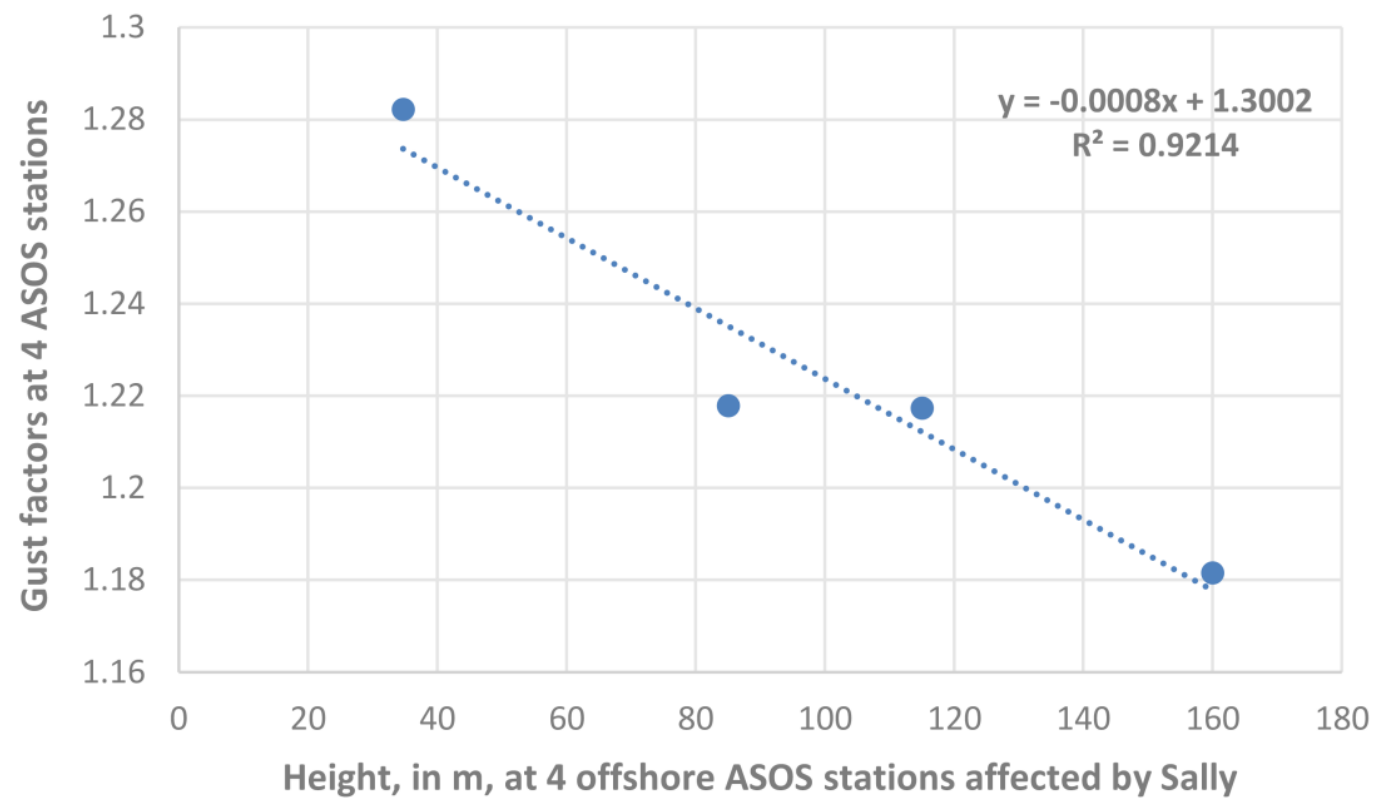

Figure 3 Variations of the gust factor with height between 34.7 and $160 \mathrm{~m}$ at the 4 ASOS locations.

The $G$ at near surface can be evaluated from two NDBC Buoys (42040 and 42012, see Figure 1 for their locations) that were also impacted by Sally. As shown in Figure 4, the $G$ at these two buoys during the passage of Sally are in good agreement with that computed using Eq. (1). Therefore, for practical applications, the near-surface value of $G=1.3$ could be a good approximation to nearsurface marine environment. 
a

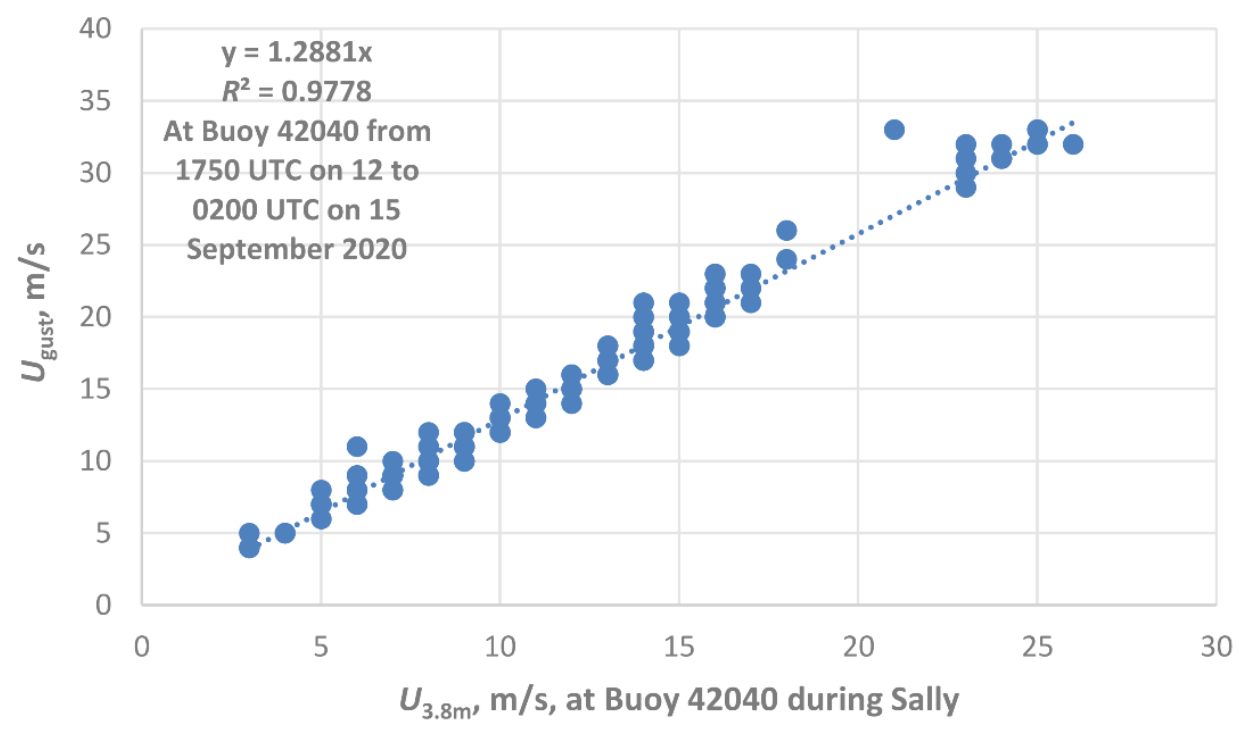

b

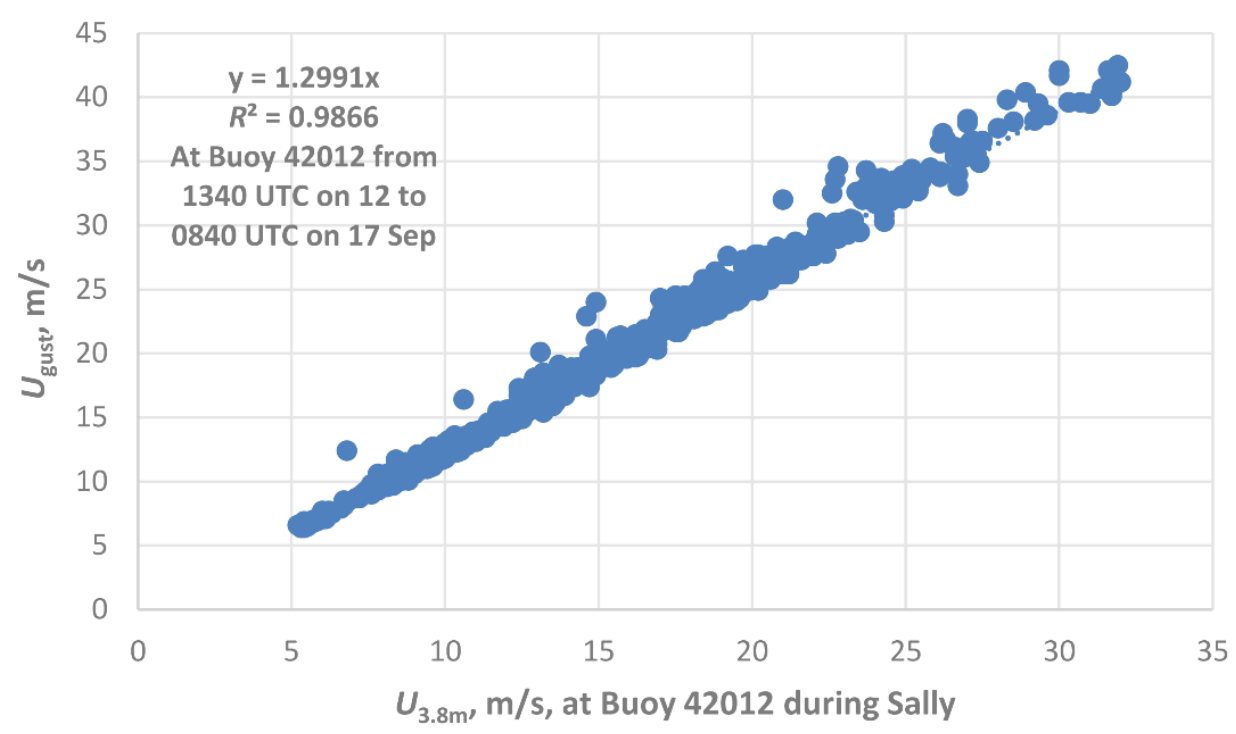

Figure 4 a) Measurements of wind speed and gust at 3.8m at NDBC Buoy 42040 before the anemometer was damaged by Sally. The height of new anemometer is $4.1 \mathrm{~m}$; $\mathbf{b}$ ) Sustained wind speed and wind gust measurements at $3.8 \mathrm{~m}$ at NDBC Buoy 42012 before, during and after the passage of Sally.

A question was raised during the review process regarding the effect of atmospheric stability on the gust factor. According to Zhang et al. [9], their Figure 9 and Hsu [10], his Table 2 among others, the stability during hurricanes could be assumed near-neutral. To verify the stability is near-neutral over the study area during the passage of Sally, a surrogate stability plot between near-surface wind speed and the air minus sea-surface temperature based on Hsu [11], his Figure 1 is presented (Figure 5). By juxtaposing Figure 5 on to that in Hsu [11], his Figure 1, the stability was near-neutral for the study area during the passage of Sally. In fact, according to the Air Resources Laboratory 
(https://www.ready.noaa.gov/READYpgclass.php Note 3), regardless of wind speed, neutral stability should be used when the sky is overcast. This is certainly the case because extensive cloud cover is an integral part of a tropical cyclone system.

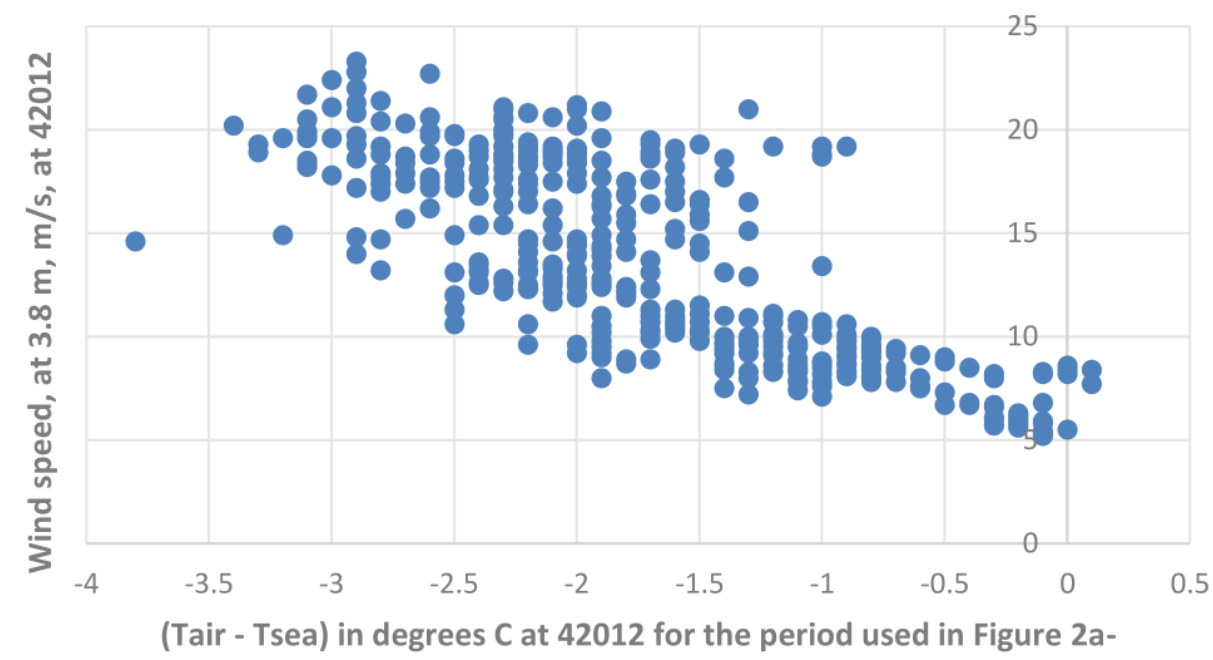

$2 d$

Figure 5 A surrogate stability plot between near-surface wind speed and the air minus sea-surface temperatures based on Hsu [11], his Figure 1.

\section{Conclusions}

For offshore wind energy R\&D and O\&M, information on gust factor variation with height during Hurricane Sally in 2020 is investigated using the anemometers data available at 4 oil rigs over the north central Gulf of Mexico. A linear equation (Eq. (1)) is found in the present study such that the $G$ decreases at a rate of approximately $8 \%$ per $100 \mathrm{~m}$ over the range from around 35 to $160 \mathrm{~m}$. This linear equation could be applied to other tropical-cyclone prone regions where such a study is lacking. On the other hand, the $G$ at near surface as extrapolated from Eq. (1) is around 1.3 which is close to the measurements made at two buoys over the study area during the passage of Sally. Thus, it is suggested that a $G$ of 1.3 could also be useful for practical applications in near-surface marine environment.

\section{Acknowledgments}

Appreciations go to NDBC and NHC for providing the datasets and Sally's track used in this study and to the three anonymous reviewers for their valuable comments.

\section{Author Contributions}

The author did all the research work of this study.

\section{Competing Interests}

The author has declared that no competing interests exist. 


\section{References}

1. Siddiqui MS, Rasheed A, Kvamsdal T, Tabib M. Effect of turbulence intensity on the performance of an offshore vertical axis wind turbine. Energy Procedia. 2015; 80: 312-320.

2. Göçmen T, Giebel G. Estimation of turbulence intensity using rotor effective wind speed in Lillgrund and Horns Rev-l offshore wind farms. Renew Energ. 2016; 99: 524-532.

3. Argyle $\mathrm{P}$, Watson $\mathrm{S}$, Montavon $\mathrm{C}$, Jones I, Smith M. Modelling turbulence intensity within a large offshore wind farm. Wind Energy. 2018; 21: 1329-1343.

4. Hsu SA. A gust-factor criterion for rapid determination of atmospheric stability and mixing height for overwater dispersion estimates. Natl Weather Dig. 2003; 27: 70-74.

5. Hsu SA. Overwater turbulence intensity during hurricane Katrina and typhoon Russ. In: Global Journal of Science Frontier Research: Marine Science Oceanography. Framingham: Global Journals; 2015. pp.1-6.

6. Wieringa J. Gust factors over open water and built-up country. Boundary Layer Meteorol. 1973; 3: 424-441.

7. Bardal LM, Sætran LR. Wind gust factors in a coastal wind climate. Energy Procedia. 2016; 94: 417-424.

8. Hsu SA, Blanchard BW. Estimating overwater turbulence intensity from routine gust-factor measurements. J Appl Meteorol. 2004; 43: 1911-1916.

9. Zhang JA, Drennan WM, Black PG, French JR. Turbulence structure of the hurricane boundary layer between the outer rainbands. J Atmos Sci. 2009; 66: 2455-2467.

10. Hsu SA. Estimating overwater friction velocity and exponent of power-law wind profile from gust factor during storms. J Waterw Port Coast Ocean Eng. 2003; 129: 174-177.

11. Hsu SA. An overwater stability criterion for the offshore and coastal dispersion model. Boundary Layer Meteorol. 1992; 60: 397-402.

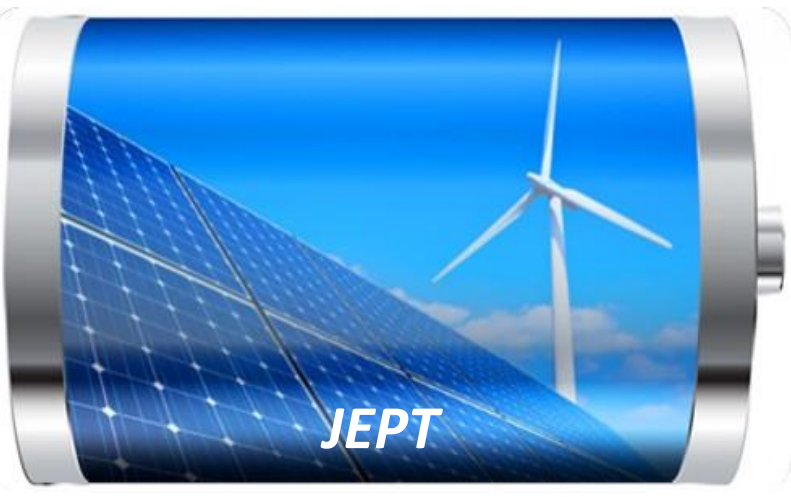

Enjoy JEPT by:

1. Submitting a manuscript

2. Joining in volunteer reviewer bank

3. Joining Editorial Board

4. Guest editing a special issue

For more details, please visit: http://www.lidsen.com/journal/jept 